\title{
SAFE CONDITIONS FOR CONTACTING NITRIC ACID OR NITRATES WITH TRI-N-BUTYL PHOSPHATE (TBP)
}

by

M L Hyder

Westinghouse Savannah River Company

Savannah River Site

Aiken, South Carolina 29808

DOE Contract No. DE-AC09-89SR18035

This paper was prepared in connection with work done under the above contract number with the U.S.

Department of Energy. By acceptance of this paper, the publisher and/or recipient acknowledges the U.S. Government's right to retain a nonexclusive, royalty-free license in and to any copyright covering this paper, along with the right to reproduce and to authorize others to reproduce all or part of the copyrighted paper. 
WSRC-TR-94-059

REV. 0

Keywords: Reaction Kinetics

Process Safety

Temperature Iimits

Retention: Iifetime

SAFE CONDITIONS FOR CONTACTING NITRIC ACID OR NITRATES
WITH TRI-N-BUTYI PHOSPHATE (TBP) (U)

M. I. HYDER

JANUARY 1994

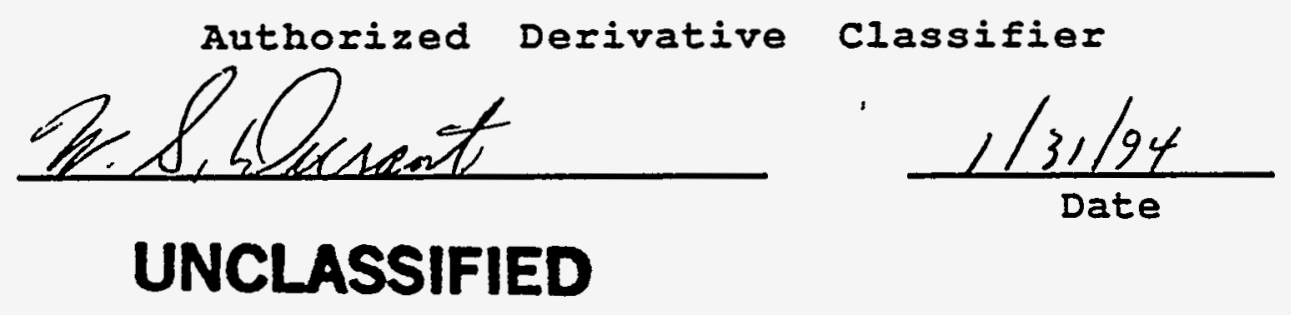

Westinghouse Savannah River Company

Savannah River Technology Center

Alken, SC 29803

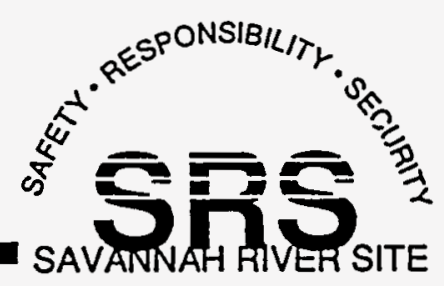

PREPARED FOR THE U.S. DEPARTMENT OF ENERGY UNDER CONTRACT NO. DE-AC09-89SR18035 
This report was prepared by Westinghouse Savannah River Company (WSRC) for the United States Department of Energy under Contract No. DE-AC09-89SR18035 and is an account of work performed under that contract. Neither the united States Department of Energy, nor WSRC, nor any of their employees makes any warranty, expressed or implied, or assumes any legal liability or responsibility for the accuracy, completeness, or usefulness, of any information, apparatus, or product or process disclosed herein or represents that its use will not infringe privately owned rights. Reference herein to any specific commercial product, process, or service by trademark, name, manufacturer or otherwise does not necessarily constitute or imply endorsement, recommendation, or favoring of same by WSRC or by the United States Government or any agency thereof. The views an opinions of the authors expressed do not necessarily state or reflect those of the United States Government or any agency thereof. 


\section{DISCLAIMER}

Portions of this document may be illegible in electronic image products. Images are produced from the best available original document. 


$$
\text { WSRC-TR-94-059 }
$$

Rev. 0

SAFE CONDITIONS EOR CONTACTING NITRIC ACID OR NITRATES WITH TRI-N-BUTYL PHOSPHATE (TBP)

M. I. HYDER

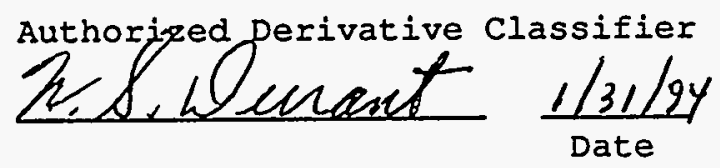

UNCLASSIFIED

Westinghouse Savannah River Company

Savannah RIver Technology Center

Alken, SC 29803

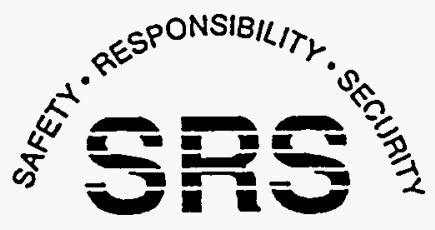

SAVANNAH RIVER SITE

PREPARED FOR THE U.S. DEPARTMENT OF ENERGY UNDER CONTRACT NO. DE-AC09-89SR18035 
Document: $\quad$ FSRC-TR-94-059

TitIe: SAFE CONDITIONS FOR CONTACTING NITRIC ACID OR NITRATES WITH TRI-N-BUTYL PHOSPEATE (TBP) (U)

Task:

APPROVALS

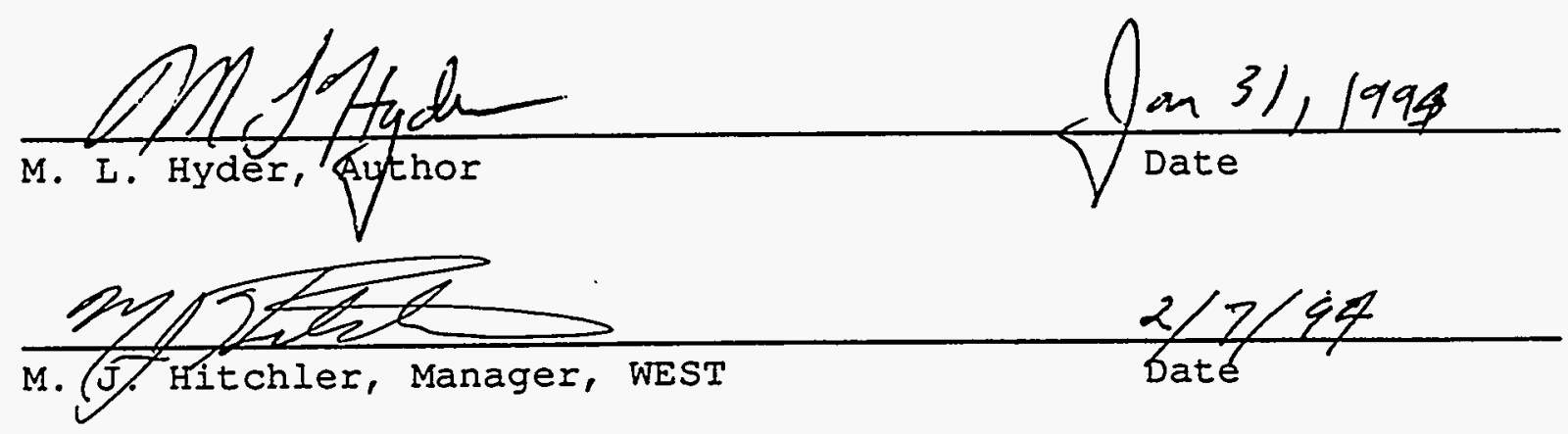




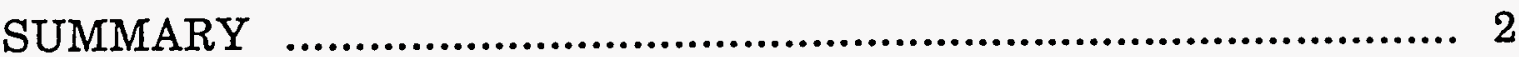

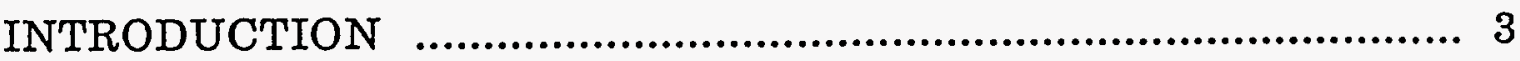

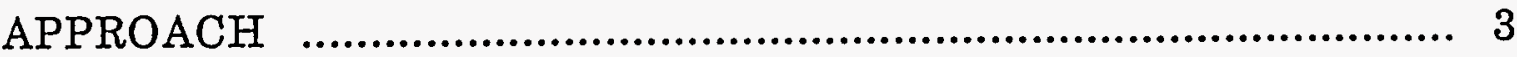

ASSUMPTIONS.................................................................... 3

RESULTS \& DISCUSSION......................................................... 3

RECOMMENDATIONS........................................................... 8

REFERENCES

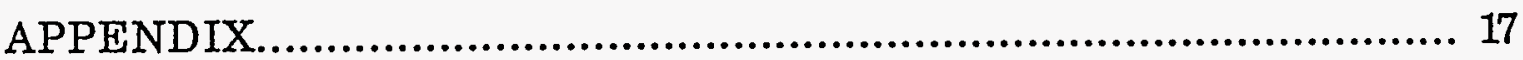

1. Comparison of Reaction Rates for TBP Hydrolysis and for the Reaction of TBP with Nitric Acid................................................ 13

2. Vapor Pressures of C4 Compounds.......................................... 14

3. Minimum Temperature for Self-Accelerating Reaction Between Nitric Acid and TBP..................................................... 15

4. Organic Layer Thickness at Heat Balance....................................... 16

1. A1. 


\section{Summary}

In response to a request from DOE-SR, the current state of knowledge of the reactions between TBP and aqueous nitrate solutions is critically reviewed, and recommendations are made for the safe operation of SRS separations equipment in which this combination of chemicals may be present. The existing limits for evaporation are validated. Guidelines are presented for cases in which general limits do not apply. Sample calculations are included in an appendix.

The rate of reaction between nitric acid and TBP appears to be controlled by the rate of TBP hydrolysis. The hydrolysis reaction produces dibutyl phosphate and $\mathrm{n}$-butanol. The hydrolysis rate is a strong function of temperature, and becomes very fast at temperatures in the range $130^{\circ}$ to $150^{\circ} \mathrm{C}$. The resulting n-butanol is volatile at high temperatures, boiling at $117.5^{\circ} \mathrm{C}$, but is also subject to exothermic oxidation by nitric acid or nitrates. If oxidation occurs before the n-butanol evaporates, the heat of oxidation may exceed local cooling by convection. The resulting heating will further accelerate the reaction, leading to an energetic runaway and possibly (in confined systems) an explosion.7,8 Extensive experiments and practice have shown that in a well-mixed and well-vented aqueous system such as an evaporator, at moderate acidities and temperatures below $130^{\circ} \mathrm{C}$, the heat of reaction is adequately removed by vaporization of steam. In general, the heating will be so slow that natural processes provide adequate cooling at temperatures below $80^{\circ} \mathrm{C}$. Above this temperature care should be taken to ensure that adequate cooling is available for the amount of TBP that may be present. Experiments suggest that in well-ventilated systems n-butanol evaporation and convective cooling are sufficient to control the reaction at temperatures up to $120^{\circ} \mathrm{C}$. 


\section{Introduction}

The contacting of tributyl phosphate (TBP) with aqueous solutions of nitric acid and acidic solutions of metal nitrates is intrinsic to the Purex separations process, and is routinely performed safely around the world. However, these reagents are also known to react exothermically at high temperatures, and such reactions have led to several damaging explosions. The most recent of these was in April, 1993, at the Tomsk-7 separations facility in Siberia. ${ }^{1}$ Several other incidents of this type (with less serious consequences) have occurred in the past in U. S. facilities. $2,3,4$

As a result of the Tomsk-7 incident, C. C. Mason requested a report on this subject as a basis for evaluating the safety of limits now used in separations operations. ${ }^{5}$ This memorandum reviews the bases for limits, and presents recommendations for future work. The bases for these limits are considered conservative. Ongoing experiments and analyses may provide additional information that will permit the removal of conservatisms. In addition, more detailed studies of the operation and ventilation of SRS tanks, evaporators, and other equipment, may enable relaxation of the indicated limits. This study is intended to provide direction as to how this may be done.

\section{Approach}

The literature on TBP-nitrate reactions was critically reviewed.

Results of the review were used in conjunction with other chemical information and heat transfer calculations to develop a consistent mechanistic picture of TBPnitrate reactions. Limits were derived on the basis of the results.

\section{Assumptions}

Rate values given by Nichols ${ }^{6}$ for the organic phase reaction of nitrate with TBP are used in the calculations. Heats of reaction are calculated by the method given by Nichols in the same report, using corrected heats of formation. These are assumed to be pertinent at temperatures up to $160^{\circ} \mathrm{C}$, which was the maximum measured by that author.

\section{Results and Discussion}

The accident at Tomsk-7 occurred in a large, quiescent tank with poor thermal coupling to the surroundings and poor ventilation. G. S. Nichols noted as early as 1960 that systems of this type, once raised to a temperature where some reaction can occur, are vulnerable to self-heating into the dangerous region. ${ }^{6}$ Additional calculations of this type have more recently been made at Los Alamos. ${ }^{10}$ It is reasonably sure that the solution in the top of the Tomsk-7 tank was added at a high temperature, probably more than $90^{\circ} \mathrm{C}$, and may not have cooled very much. ${ }^{1,9}$ Current (not yet documented) experiments by M. C. Thompson and W. $\mathrm{S}$. Cavin at SRS suggest that the mixed layer was further heated by $10^{\circ}$ to $20^{\circ}$ by 
the heat of nitric acid dilution. In the Tomsk-7 incident it is also likely that degraded organic material was present, which may have been more reactive than TBP. Thus a mechanism existed for reaching temperatures of $90^{\circ} \mathrm{C}$, or even higher. This is the temperature range in which a well-insulated mixture may begin to react, according to Nichols' calculations.

Thus the Tomsk-7 incident does not appear to introduce any new reaction mechanisms or chemistry. Rather, it shows that the safety criteria developed for one type of system (a well-mixed aqueous system with vigorous boiling) do not necessarily apply in an entirely different system where heat removal is poor. There is little doubt that the Tomsk-7 incident would have been prevented if a relatively small amount of effective cooling were present at the upper reactive layer, or even if the vessel had been stirred so that the cooler solution near the bottom could have lowered its temperature. The lesson is that safety analyses must take into account heat removal as well as heat generation. This document presents some specific recommendations for handling TBP-nitrate mixtures, taking heating, cooling, and other factors into account.

\section{Reactions of Nitric Acid and Nitrates With TBP}

TBP, when contacted with nitric or other acids and water, undergoes slow hydrolysis to produce butanol and di-butyl phosphate (DBP).11,12 This is the reverse reaction to the esterification that formed the TBP. Hydrolysis occurs both in aqueous solution, where there is a small amount of dissolved TBP, or in the organic phase, into which the nitric acid is extracted. (Such solutions also contain a small amount of water). The first-order rate constant for hydrolysis in the presence of nitric acid is of the order of $10^{-6} \mathrm{hr}^{-1}$ at $20^{\circ} \mathrm{C}$, and increases to about $0.005 \mathrm{hr}^{-1}$ near $100^{\circ} \mathrm{C} .12$ It is a function of acid concentration as well: 6 Further hydrolysis of the DBP will also occur, but at a slower rate, and eventually phosphoric acid and butanol are produced.

At high temperatures energetic reactions of TBP and nitric acid occur, which plausibly involve the hydrolysis reaction to butanol and DBP as a first step. The butanol can react with nitric acid to form butyl nitrate, the ester of butanol and nitric acid. However, because strong nitric acid oxidizes organic material and alcohols in particular, further reactions may occur, leading to the partial oxidation of butanol. The oxidation reactions are exothermic, so under favorable conditions they may accelerate the overall reaction between TBP and nitric acid. Metal nitrates, such as uranyl nitrate, can also oxidize TBP at high temperatures. 4,6-8 Experience has shown that such exothermic reactions, generating copious amounts of gas $\left(\mathrm{CO}, \mathrm{CO}_{2}\right.$, steam, nitrogen and its oxides), can proceed with explosive violence in confined vessels. $1-4,6-8,13$

There is a reasonably close agreement between the reaction data developed by Nichols 6 and the data cited by Schulz and Navratil on TBP hydrolysis in the presence of nitric acid 12 , at least up to $70^{\circ} \mathrm{C}$. (Figure 1) This tends to confirm that at temperatures within this range hydrolysis is the controlling step in the reaction. Recent work at Hanford confirms that nitric acid - butanol reactions proceed at relatively low temperatures, even at room temperature if the acid is 
strong enough. 14 This raises concerns for TBP that has been in contact with acid for a long time, so that some thermal hydrolysis may have occurred. Such solutions may react with acid at a lower temperature than those in which hydrolysis has not occurred. Before heating or evaporating such solutions, this potential reaction should be evaluated.

The presence of an aqueous phase containing strong nitric acid is important not only in forming the initial TBP-nitric acid complex in the organic phase, but as a potential source of additional nitric acid.

The hydrolysis reaction and secondary reactions are dependent on the nitric acid concentration. Nichols' data show a relatively modest rate dependence (a factor of about six) in going from $1.5 \mathrm{M}$ uranyl nitrate with $3 \mathrm{M}$ nitric acid in the original aqueous phase to high concentrations $(10 \mathrm{M})$ of nitric acid only in that phase; but his experiments involved only the separated organic phase. 6 Hanford data show that the temperature at which the butanol-nitric acid reaction is initiated depends on acid concentration. ${ }^{14}$ (Note that although alkaline solutions will also hydrolyze TBP, the heating of TBP with alkalis is not a safety concern, because alkaline nitrate is not a strong oxidant.)

Also, at high temperatures in the presence of metal nitrates, there is evidence that a pyrolysis reaction occurs:

$\mathrm{OP}\left(\mathrm{OC}_{4} \mathrm{H}_{9}\right)_{3}--\Delta-->\mathrm{H}_{3} \mathrm{PO}_{4}+3 \mathrm{C}_{4} \mathrm{H}_{8}$

Harmon et al. 4 identified the butene produced by this reaction as a major gaseous product, and probably the major contributor to the explosion in the A-Line at the Savannah River Plant. Their thermogravimetry data indicated that this reaction begins only above $130^{\circ} \mathrm{C}$. Depending on conditions some oxidation or pyrolysis of the butene may also occur, yielding butanoic acid, degraded hydrocarbons, etc. Similar findings have also recently been made at Hanford. ${ }^{22}$

Wagner observed reaction of "red oil" systems containing nitrated diluent occurring at lower temperatures than pure TBP. 3 These experiments also involved an uncertain amount of butanol produced during reflux; however, it was believed that most of the butanol (b. p. $117.5^{\circ} \mathrm{C}$ ) had evaporated or reacted before exothermic reactions became important. Wagner's data show reaction beginning in some cases as low as $120^{\circ} \mathrm{C}$. The significance of the nitrated diluent in these experiments, which gives the "red oil" its color, is not well established. Gordon's data from confined systems show significant reaction in this complex at comparable temperatures. ${ }^{7,8}$

\section{Physical Effects}

Physical phenomena of interest in this system include foaming, pressure effects, and the effects of confinement, including the evaporation of butanol and/or its nitrate ester. 
Foaming in the organic phase occurs as the self-heating accelerates, because of the gases generated, and continues to considerably higher temperatures. Copious amounts of foam are reported when TBP-uranyl nitrate adduct is heated to a high temperature. 4 Foaming provides a mechanism for plugging vents, or bubble caps as appears to have occurred in the TNX incident. ${ }^{2}$ In addition, the foam can be thermally isolated from the rest of the system because of its good insulating qualities. A foaming mass that is undergoing an exothermic reaction may therefore attain a higher temperature than a liquid in contact with a heat sink, such as water.

The Russian operators of Tomsk- 7 did not find evidence of foaming in their postaccident analysis. ${ }^{15}$ However, it is doubtful that their instruments would have detected it, and the laboratory data make it almost certain that foaming occurred. Possible consequences include partial or complete plugging of offgas lines, and an acceleration of the reaction as the result of heating in the foam phase.

The effect of pressure on the reaction is indirect. Neither the hydrolysis nor the pyrolysis reactions should be affected greatly by pressure changes. However, a higher pressure permits higher steam temperatures, and hence higher temperatures in an associated aqueous phase.

The effects of confinement are complex, and important. First, a closed system is not cooled by evaporating water. In the Los Alamos calculations, which included water evaporation, the loss of this cooling process determined the rate at which the TBP-nitric acid reaction proceeded and accelerated. ${ }^{10}$ Chemical effects can also be affected by confinement. Gordon saw little difference in the course of reaction up to $125^{\circ}$ between closed and open systems. 7,8 However in a closed system such as he studied, volatile products cannot escape and may become involved in further reactions at temperatures above $125^{\circ}$. In particular, it appears that truly explosive reactions require a system that is effectively confined. Gordon observed pressure increases at explosive rates in a pressure vessel with a limited head space. 7,8 Studies of similar systems in open laboratory vessels showed only a transition to a much faster reaction with copious foam generation. ${ }^{3}$ A recent experiment by Cavin in an open vessel showed foaming only after much of the water present had been evaporated. 18 There appears to be no report in the literature of a truly violent reaction in a system with substantial venting.

The product of the hydrolysis reaction, butanol, and its first reaction product with nitric acid, butyl nitrate, are both volatile under the conditions of interest here. nButanol boils at $117.5^{\circ} \mathrm{C}$, and butyl nitrate at $135.5^{\circ} \mathrm{C} .19$ (Figure 2) If the rates of oxidation of these substances are slow compared to their evaporation rates, they will be removed from the system before they can be oxidized and produce heat. The intermediate products of the reduction of nitric acid are also volatile. The rate at which these materials boil away is controlled by a number of factors, including the thickness of the organic layer, evaporation of steam (if any), and the ventilation rate in the vapor space. The other term, the reaction rate of these materials in the liquid phase, should be a function of nitric acid concentration as well as temperature. This variable of evaporation rate may account for some of 
the discrepancies and variations among different experiments, and the removal of these reactive compounds provides an added safety factor that has not been generally appreciated. The results of Scott and Barney indicate that the effect of reactant loss by evaporation can be very large, reducing the heating by as much as $90 \%$ under favorable circumstances; 22 additional discussion of this point is in the Appendix.

\section{Heat Transfer Considerations}

Nichols 6 pointed out the importance of heat transfer in determining whether an exothermic reaction will self-accelerate, and this has been further emphasized by the Los Alamos calculations. ${ }^{10}$ The evaporation of water can be an effective cooling system, and so long as the system is so configured that any heat generated can evaporate water, and the temperature remains below a critical temperature, a runaway reaction cannot occur. This is substantiated by forty years of successful operation of the Savannah River evaporators, which are limited to $<130^{\circ} \mathrm{C}$. The material that generated the A-Line accident at SRS had passed through such an evaporator uneventfully. In the evaporator there is reasonably good mixing, so that thermal gradients are minimized, and the heat input from either steam coils or internal reaction goes into evaporating water.

In the absence of steam generation heat transfer is much poorer. Nichols calculated the heat transfer through the walls of tanks of various sizes and related this to the temperature at which self-heating becomes important. ${ }^{6}$ (Figure 3) His calculations appear to have considered only heat transfer through the side walls in contact with the organic layer, and through the top of the tank; they do not include heat lost to the underlying aqueous phase or through the side walls of a heated vapor space. Neither did they deal with the cooling effect of ventilation of the air space, nor allow for the potential loss of reactants such as butanol. Significant uncertainty is also introduced into this kind of calculation by uncertainties in the heat transfer coefficient for convective cooling by the outside air. ${ }^{16}$ Nichols' calculations were nonetheless useful in indicating the region of concern for heat transfer. Note that the thermodynamic data for butanol and butanoic acid used by Nichols appear to have been incorrect; recalculation as shown in the Appendix has given higher values of energy, which would correspond to lower temperatures of self-heating than those shown in Figure 3. This is discussed in more detail in the Appendix.

Applying Nichols' calculations must be done cautiously. For example, in the cell at Tomsk-7 the temperature of the air surrounding the tank may well have been hotter than the $80^{\circ} \mathrm{F}\left(27^{\circ} \mathrm{C}\right)$ which Nichols assumed in his calculation, so that heat loss to the surroundings was less efficient. Heat loss through ventilation appears to have been poor. The heat losses to the aqueous phase were low, because the temperature of the aqueous layer in contact with the organic phase and that of the organic phase were nearly the same. Consequently, the Tomsk-7 incident may have started with an organic temperature as low as $90^{\circ} \mathrm{C}$. 


\section{Experimental Programs}

There are several questions regarding the role of butanol in these reactions that need additional resolution. Experiments are in progress to obtain some of the required data. These should make possible specific limits for handling partially hydrolyzed TBP.

The Savannah River Technical Center is measuring the distribution of butanol between the organic and aqueous phases in PUREX systems. This is necessary to determine in which phase the butanol-nitric acid reactions will occur. These experiments are expected to be completed by March 31, 1994.

Recently concluded experiments by Westinghouse Hanford measured reaction rates, energetics, and gaseous products in the reaction of nitric acid/nitrate with TBP at elevated temperatures. ${ }^{22}$ In general the conclusions support the mechanisms given above. The most important results of these experiments were the energetic measurements, which support the conclusion given above about loss of reactants from the liquid phase by evaporation. The observed exothermic heating in these well-ventilated experiments did not exceed $147 \mathrm{~J} / \mathrm{g}$.

\section{Recommendations}

The following recommendations are made for the safe handling of TBP-nitrate mixtures, based on considerations given above, and calculations of the type shown in the appendix. Note that these calculations apply only to the separated organic phase, and the temperature cited is the temperature of that phase. This will in general imply that mixing must be adequate to ensure that the aqueous and organic phases are at a uniform temperature. For these calculations it is also assumed that the organic phase is pure TBP. SRS diluents are essentially inert under the conditions of interest, and will evaporate at the higher temperatures.

The small amount of TBP dissolved in the aqueous phase is not a concern, as the heating and evaporation of the water constitutes a sufficient heat sink for the relatively small amount of heating that might result.

1. Maximum temperature for acidic nitrate evaporation of aqueous solutions potentially containing TBP: $130^{\circ} \mathrm{C}$

This number is based on a variety of experimental evidence, and is valid when the conditions of mixing and heat transfer ensure that reaction heat will evaporate water. This is generally the case in evaporators. This limit does not apply to alkaline waste evaporators, in which there is no concern for nitrate-organic reactions.

Supporting data for this value include:

a. Colven, et al., found in laboratory experiments that reactions were initiated at about $130^{\circ}$ or higher, depending on composition. ${ }^{2}$ 
b. Nichols found reaction initiating in a chamber in laboratory experiments at this temperature. ${ }^{6}$

c. Nichols' calculated data show that organic solutions at depths of an inch or so will begin to react spontaneously at this temperature. (Fig. 2)

d. Harmon et al. obtained thermogravimetric data showing decomposition beginning at this temperature on a fast time scale. ${ }^{4}$

e. Gordon made sealed vessel experiments of reactions in TBP-metal nitrate systems. His data showed spontaneous reaction beginning only at temperatures significantly higher than this. 7,8

f. Hanford data showing reactions initiating only at higher temperatures in well-ventilated systems. ${ }^{22}$

This value has been used historically as a limit for SRS evaporators, with success. 24

2. Maximum temperature for TBP in quiescent systems contacted with aqueous uranyl nitrate, and/or nitric acid, up to $10 \mathrm{M}: 120^{\circ} \mathrm{C}$

This limit applies to those quiescent systems in which heat removal by steam may not be efficient. It is based on experimental observations that show that in wellventilated systems runaway reactions are not observed at this temperature. In addition, the calculations given in the Appendix indicate that convective cooling alone can remove the heat from a substantial amount of adduct at this temperature. (The exact amount is a function of acidity and ventilation conditions.) Laboratory measurements show that self-sustaining reactions generally occur at temperatures of $130^{\circ} \mathrm{C}$ or higher in ventilated systems..$^{2,3,4,18,22}$ Note, however, that in poorly ventilated systems, such as the closed vessel experiments of Gordon, self-heating has been observed at temperatures as low as $120^{\circ} \mathrm{C} .7$ Thus this limit only applies to well-ventilated vessels.

This limit is most important in acidic evaporations of waste solutions with little or no uranium present. While limit \#1 would apply to the evaporation itself, in which heat removal by steam is efficient, the bottoms left at the conclusion of evaporation are the concern. By applying only limit \#1, they could be discharged or allowed to remain in the evaporator at temperatures above $120^{\circ} \mathrm{C}$ without cooling. It is important that the vessel containing these hot solutions be well ventilated; agitation, to prevent stratification and allow the evaporation of water, would provide additional cooling.

As the potential for self-heating of these already hot solutions is the concern, a satisfactory alternative to this limit would be to demonstrate that either (a) adequate cooling is present to remove chemical heat, or (b) the quantity of TBP present is so small that heating is negligible. Conversely, this limit should not be applied to any vessel that is not either well mixed or well ventilated. In such cases there is no assurance that an adequate cooling method is available. 
3. Maximum temperature for normal handling of acidic process solutions that may contain TBP: $85^{\circ} \mathrm{C}$.

"Normal handling" refers to activities other than evaporation, and the handling of product solutions immediately following evaporation. This limit is based on reaction rates given by Nichols, ${ }^{6}$ which indicate that at this temperature the reaction rates are so low that ordinary ventilation and other cooling mechanisms can easily remove the heat produced. See the Appendix for calculations supporting this conclusion.

\section{Alternative Limits of Mass or Concentration}

In some cases it may be desirable to control the amount of TBP present rather than the temperature or heat transfer. There is currently a limit of $0.5 \% \mathrm{TBP}$ in the agitated feed to an evaporator. ${ }^{24}$ However, such limits must be used with care, since in large vessels they would permit accumulation of substantial volumes of TBP. The 1953 evaporator incident appears to have involved only about 40 liters of TBP. It is therefore apparent that control by concentration alone would not be adequate unless it could be established that the potential accumulations of TBP would be safe under the prevailing conditions.

A more useful criterion might be the mass of TBP per unit surface area, since this can be related to the cooling processes. Heat generation would be proportional to mass, and cooling to the surface area. A specific calculation for each case of interest would be required. An example of such calculations is given in the. Appendix.

\section{References}

1. F. C. Gilbert, F. E. Witmer, R. E. Felt, L. W. Gray, M. L. Hyder, L. H. Sullivan, and D. D. Wodrich, "Trip Report, Moscow and Tomsk, Russia, June 19-29, 1993", DOE/DP-0120, September, 1993.

2. T. J. Colven, Jr., G. M. Nichols, and T. H. Siddall, "Interim Technical Report, TNX Evaporator Incident January 12, 1953", DP25, May 15, 1953.

3. Robert M. Wagner, "Investigation of Explosive Characteristics of Purex Solvent Decomposition Products (Red Oil)", HW-27942, March 17, 1953.

4. H. D. Harmon, M. L. Hyder, B. Tiffany, L. W. Gray, and P. A. Soltys, "Behavior of Tributyl Phosphate in A-Line Processes", DP-1418, August, 1976.

5. C. C. Mason, Letter to R. Maher, October 6, 1993. 
6. G. S. Nichols, "Decomposition of the Tributyl Phosphate - Nitrate Complexes", DP-526, November, 1960.

7. Letter, R. J. Gordon to S. T. Augsberger, "Environmental TestingExplosion Hazards Tributylphosphate (TBP) / Nitrate Stability", October 9, 1984.

8. Letter, R. J. Gordon to S. T. Augsberger, "Environmental TestingExplosion Hazards Tributylphosphate (TBP) / Nitrate Stability", May 15, 1985.

9. M. L. Hyder, "Trip Report: Meeting on Tomsk-7 Accident, Richland, Washington, September 24-25, 1993", SRT-SAE-930342, September 30, 1993.

10. Steve Agnew, Rich Davidson, Steve Eisenhawer, Bob Fujita, Ralph Nelson, Ed Rodriguez, Jay Spore, Harold Sullivan, and Jack Travis, "Los Alamos Analysis of the Tomsk Incident", presentation to the U. S. Russian Federation meeting on radiochemistry processing safety, Richland, Washington, September, 1993.

11. L. L. Burger, "The Chemistry of Tributyl Phosphate, A Review", HW40910, October 27, 1955.

12. W. W. Schulz and J. R. Navritil, Science and Technology of Tributyl Phosphate, Vol. I, CRC Press, Inc., Boca Raton, FL, 1984.

13. D. O. Campbell and J. C. Mailen, "The Red-Oil Problem and its Impact on Purex Safety", ORNL/TM-10798, June, 1988. This was used as a source for reference to two other studies:

13a. R. G. Wilbourn, "Safety Aspects of Solvent Nitration in HTGR Fuel Reprocessing, GA-A14372 (1977).

13b. L. Stieglitz, R. Becker, H. Bautz, and R. Will, "Properties of Heavy Organic Phases and Their Formation in the Purex Process", Proceedings of the International Solvent Extraction Conference ISEC 86, 11-16 Sept., 1986, p. I-201.

14. R. C. Roal, "Red Oil Support at Hanford", presentation to the U. S. /Russian Federation meeting on radiochemistry processing safety, Richland, Washington, September, 1993.

15. V. M. Korotkevich, discussions at the U. S. /Russian Federation meeting on radiochemistry processing safety, Richland, Washington, September, 1993.

16. R. B. Bird, W. E. Stewart, and E. N. Lightfoot, Transport Phenomena, John Wiley and Sons, New York, 1960, p. 393. 
17. Wendell L. Latimer, Oxidation Potentials, Second Edition, PrenticeHall, Englewood Cliffs, N. J., 1952.

18. W. S. Cavin, SRTC, private communication.

19. Robert C. Weast, Ed., Handbook of Chemistry and Physics, 46th Edition, Chemical Rubber Co., Cleveland, Ohio, 1965.

20. S. Eisenhawer et al., Los Alamos National Laboratory, Appendix B to the Tomsk Report: "An Interim Report on Modeling of the Tomsk Incident", to be published by USDOE.

21. L. C. Burmeister, Convective Heat Transfer, Wiley, 1983.

22. G. S. Barney and T. D. Cooper, The Chemistry of Tributyl Phosphate at Elevated Temperatures in the Plutonium Finishing Plant Process Vessels, WHC-EP-0737 (Draft), January 18, 1994.

23. M. V. Vladimirova, I. A. Kulikov, and A. A. Kuprii, "Thermal Oxidation and Nitration of Systems of Tri-n-Butyl Phosphate and Diluent, Atomnaya Energiya, 71, 4, 337 (October 1991), English translation by Plenum Publishing Co., 1992, p. 838.

24. Operational Safety Requirements for 200-F and 200H Separations Areas (Excluding Tritium and Waste Management), DPW-85-101, Revision 1, Item 1.1.C.5. (February 1989). 


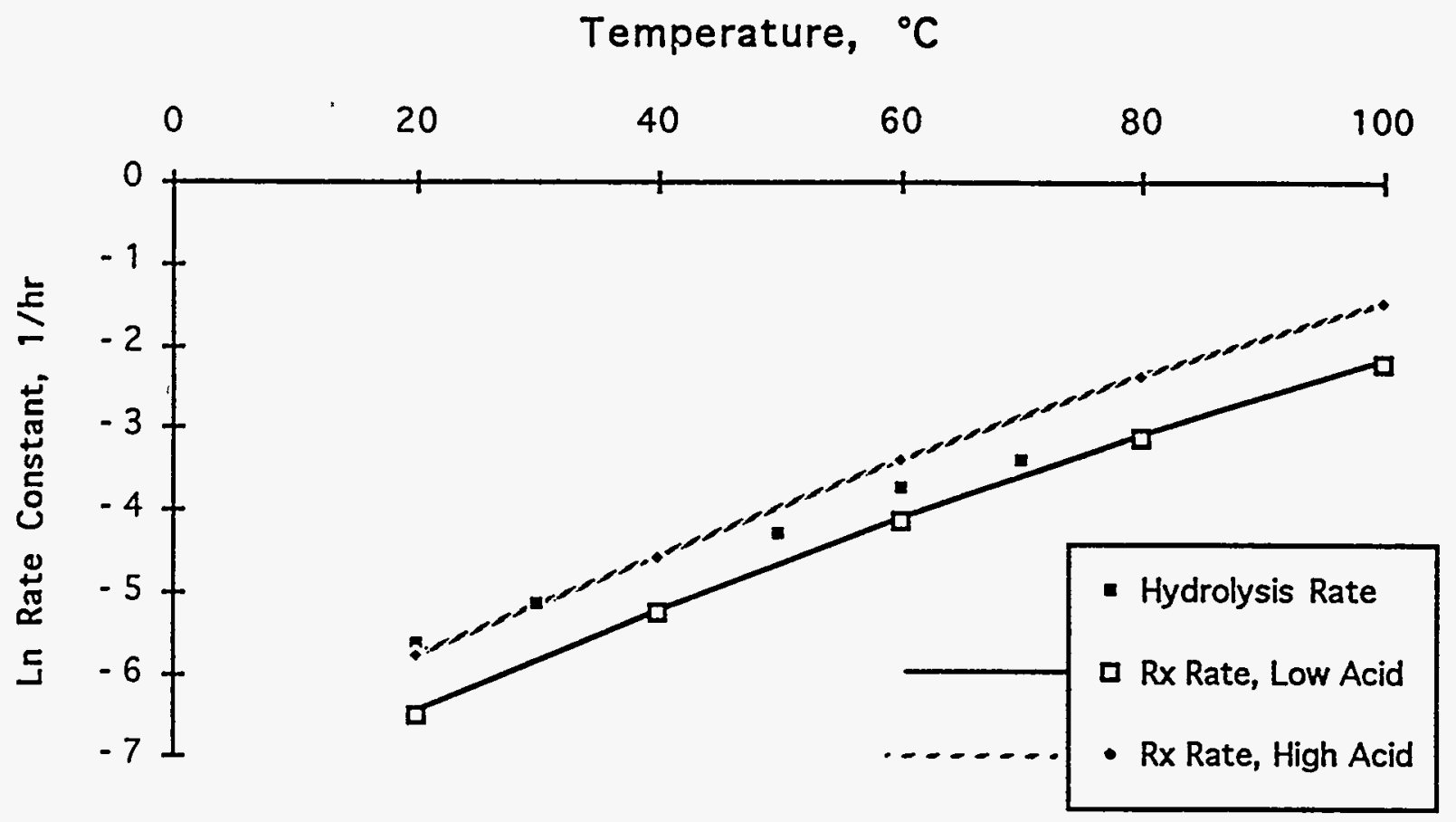

Figure 1. Comparison of Reaction Rates for TBP Hydrolysis and for the Reaction of TBP with Nitric Acid

"Hydrolysis Rate" is a composite of rate data for 100\% TBP in contact with an aqueous phase containing $5 \mathrm{M}^{\mathrm{H}} \mathrm{HNO}_{3}$. (Ref. 12, Vol. 1, p. 142, Table 3 )

"Rx Rate, Low Acid" is for a TBP solution prepared by contacting with $1.5 \mathrm{M}$ uranyl nitrate and 3.0 $\mathrm{M} \mathrm{HNO}_{3}$. (Ref. 6)

"Rx Rate, High Acid" is for a TBP solution prepared by contacting with 6 to $11 \mathrm{M}$ HNO3. (Ref. 6)

Reaction rates are calculated from parameters given by Nichols. (Ref 6) 
Figure 2: Vapor Pressures of $\mathrm{C} 4$ Hydrocarbons

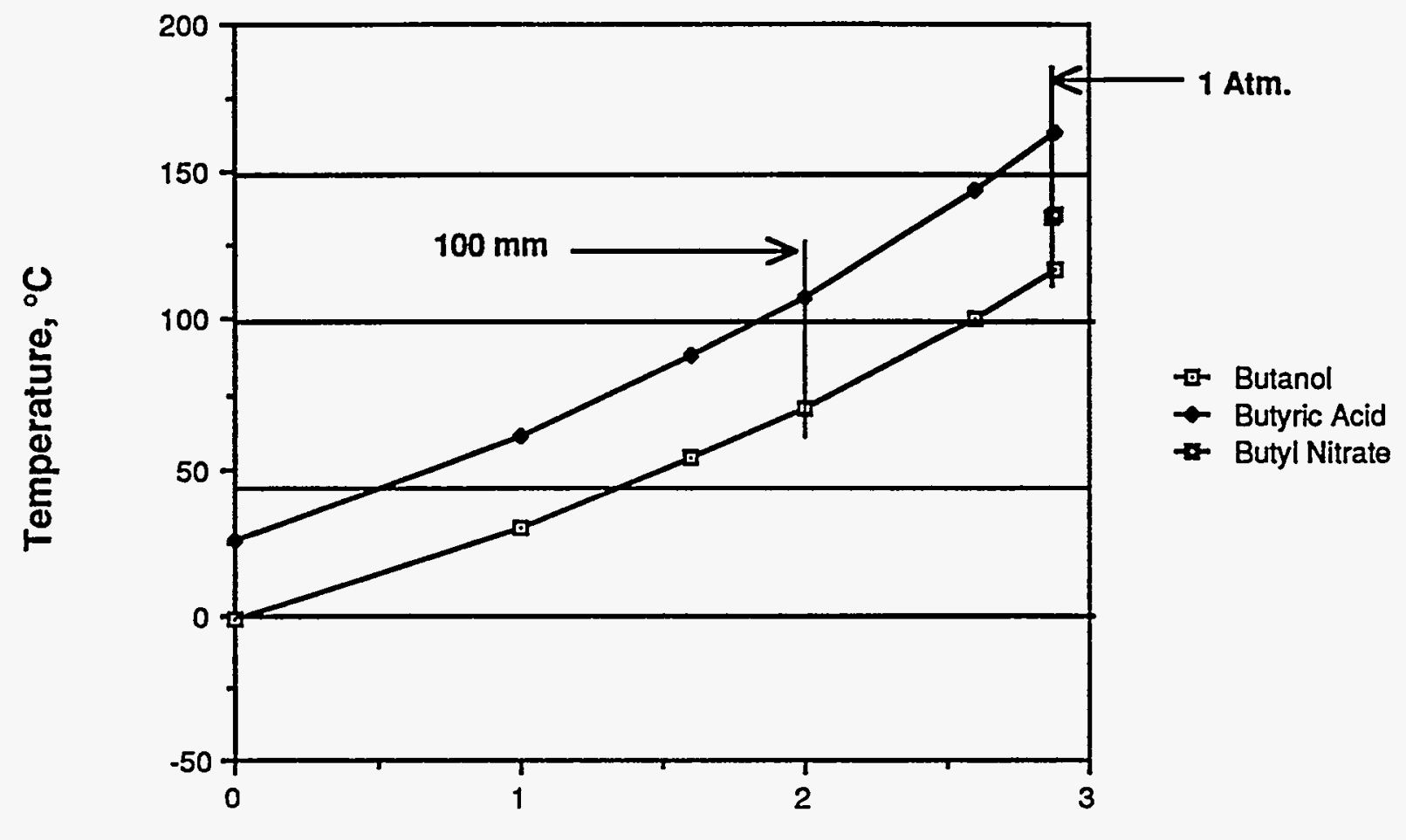

Log of Vapor Pressure, $\mathrm{mm} \mathrm{Hg}$ 


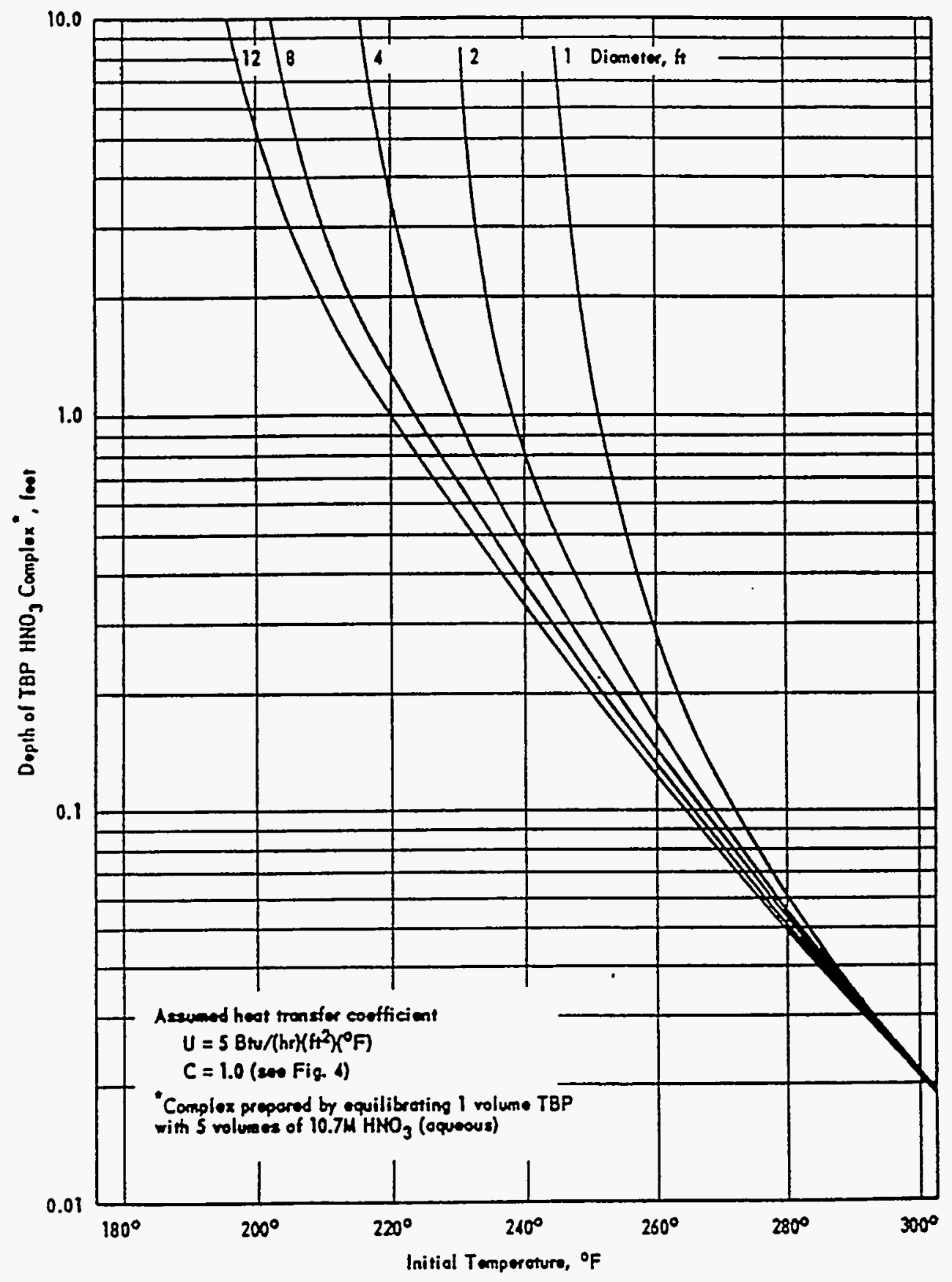

Figure 3. Minimum Temperature for Self-Accelerating Reaction Between Nitric Acid and TBP

Calculated for a vertical right circular cylinder; from Ref. 6 
Figure 4: Organic Layer Thickness at Heat Balance

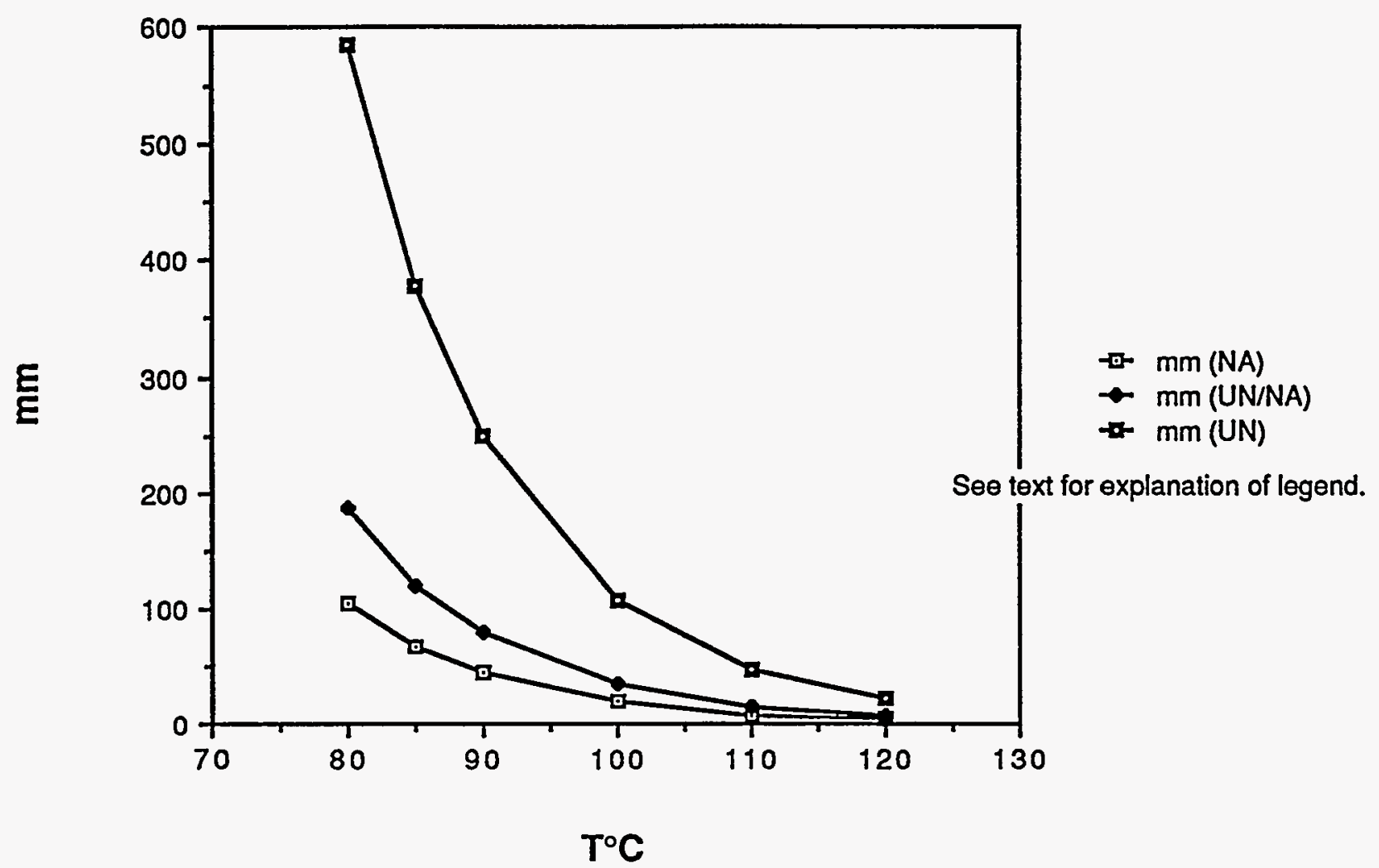




\section{Appendix: Heat Calculations Relating to TBP Decomposition}

This appendix summarizes calculations relating to the self-heating of the TBPnitrate (or nitric acid) adduct and the cooling requirements for handling such adducts in process vessels.

\section{Heat Generation}

From thermodynamic data the total heat generated by the complete oxidation of TBP to carbon dioxide, phosphoric acid, and water, by nitric acid is calculated to be about $1610 \mathrm{kcal} / \mathrm{mole}$ TBP or about $6050 \mathrm{kcal} / \mathrm{kg}$ TBP. This is based on the following equation and heats of formation:

$$
\left(\mathrm{C}_{4} \mathrm{H}_{9}\right)_{3} \mathrm{PO}_{4}+14.4 \mathrm{HNO}_{3}--->12 \mathrm{CO}_{2}+7.2 \mathrm{~N}_{2}+19.2 \mathrm{H}_{2} \mathrm{O}+\mathrm{H}_{3} \mathrm{PO}_{4}
$$

$\Delta \mathrm{H}^{\circ} \mathrm{HNO}_{3}(\mathrm{aq})=-49.4 \mathrm{kcal} / \mathrm{mole}$

$\Delta \mathrm{H}^{\circ}\left(\mathrm{C}_{4} \mathrm{H}_{9}\right)_{3} \mathrm{PO}_{4}=-425 \mathrm{kcal} / \mathrm{mole}$

$\Delta \mathrm{H}^{\circ} \mathrm{CO}_{2}=-94.1 \mathrm{kcal} / \mathrm{mole}$

$\Delta \mathrm{H}^{\circ} \mathrm{H}_{2} \mathrm{O}(\mathrm{l})=-68.3 \mathrm{kcal} / \mathrm{mole}$

$\Delta \mathrm{H}^{\circ} \mathrm{H}_{3} \mathrm{PO}_{4}=-306.2 \mathrm{kcal} / \mathrm{mole}$

The heat of formation of TBP is derived from the above data and a published heat of combustion of $-6877 \mathrm{cal} / \mathrm{g}$ ( $1830 \mathrm{kcal} / \mathrm{mole}), 11$ assuming the combustion products are carbon dioxide, liquid water, and phosphoric acid. Other $\Delta \mathrm{H}^{\circ}$ values are taken from the compilation by Latimer. 17 For this treatment, temperature variations are ignored, and all calculations are done using values derived for $25^{\circ} \mathrm{C}$.

Nichols 6 used experimental data for the decomposition of the TBP-nitric acid adduct to obtain an average heat generation rate of $179 \mathrm{kcal} / \mathrm{kg}$ at $120^{\circ} \mathrm{C}$. However, some of the thermodynamic data cited by Nichols were incorrect. Eisenhawer et al. have used Nichols' measurements with more recent data to derive a value of $379 \mathrm{kcal} / \mathrm{kg} .20$ In the following paragraphs this value is again calculated using Nichols' data, but the products are corrected to allow for the production of carbon monoxide as one of the products.

Nichols found the following products from the reaction of TBP and nitric acid: water, carbon dioxide, nitrogen, nitrous oxide, butyrates. In addition, a Russian source indicates that $\mathrm{CO}$ is produced in a ratio of about 1:3 to nitrogen. ${ }^{23} \mathrm{CO}$ would have been reported as nitrogen in Nichols' measurements, and probably also in the experiments of Barney and Cooper ${ }^{22}$; hence, $\mathrm{CO}$ is assumed to correspond to $25 \%$ of the nitrogen as reported, the remaining $75 \%$ being nitrogen. The amount of butyrates produced was small, but it is likely that some butanoic acid would have condensed or been absorbed and hence not been reported. Butanoic acid must therefore be treated as an unknown. 
To determine the thermochemistry of the reaction, it is treated as a linear weighted sum of the following six reactions:

(1) $\mathrm{C}_{4} \mathrm{H}_{10} \mathrm{O}$ (n-butanol) $+4.8 \mathrm{HNO}_{3} \longrightarrow 4 \mathrm{CO}_{2}+7.4 \mathrm{H}_{2} \mathrm{O}+2.4 \mathrm{~N}_{2}$

(2) $\mathrm{C}_{4} \mathrm{H}_{10} \mathrm{O}$ (n-butanol) $+3.2 \mathrm{HNO}_{3} \longrightarrow 4 \mathrm{CO}+7.4 \mathrm{H}_{2} \mathrm{O}+1.6 \mathrm{~N}_{2}$

(3) $\mathrm{C}_{4} \mathrm{H}_{10} \mathrm{O}$ (n-butanol) $+6 \mathrm{HNO}_{3} \longrightarrow 4 \mathrm{CO}_{2}+7 \mathrm{H}_{2} \mathrm{O}+3 \mathrm{~N}_{2} \mathrm{O}$

(4) $2 \mathrm{HNO}_{3} \longrightarrow \mathrm{H}_{2} \mathrm{O}+\mathrm{N}_{2}+2.5 \mathrm{O}_{2}$

(5) $5 \mathrm{C}_{4} \mathrm{H}_{10} \mathrm{O}$ (n-butanol) $+4 \mathrm{HNO}_{3} \longrightarrow 5 \mathrm{C}_{4} \mathrm{H}_{8} \mathrm{O}_{2}$ (butanoic acid) $+7 \mathrm{H}_{2} \mathrm{O}$ $+2 \mathrm{~N}_{2}$

(6) $\left(\mathrm{C}_{4} \mathrm{H}_{9} \mathrm{O}\right)_{3} \mathrm{PO}_{4}(\mathrm{TBP})+3 \mathrm{H}_{2} \mathrm{O} \longrightarrow 3 \mathrm{C}_{4} \mathrm{H}_{10} \mathrm{O}+\mathrm{H}_{3} \mathrm{PO}_{4}$

The energetics of these reactions are computed from the following data:

Compound Heat of Formation, $\mathrm{kcal} / \mathrm{mole}$ Source

$\begin{array}{lll}\mathrm{C}_{4} \mathrm{H}_{10} \mathrm{O} \text { (n-butanol) } & -78.2 & \text { LANL } \\ \mathrm{C}_{4} \mathrm{H}_{8} \mathrm{O}_{2} \text { (butanoic acid) } & -126.5 & \text { LANL } \\ \mathrm{CO}_{2} & -94.1 & \text { Latimer } \\ \mathrm{CO} & -26.4 & \text { Latimer } \\ \mathrm{H}_{2} \mathrm{O}(\mathrm{l}) & -68.3 & \text { Latimer } \\ \mathrm{HNO}_{3} \text { (aq) } & -49.4 & \text { Latimer } \\ \mathrm{N}_{2} \mathrm{O} & 19.5 & \text { Latimer } \\ \left(\mathrm{C}_{4} \mathrm{H}_{9} \mathrm{O}\right)_{3} \mathrm{PO}_{4} \text { (TBP) } & -425 & \text { Derived } \\ \mathrm{H}_{3} \mathrm{PO}_{4} & -306.2 & \text { Latimer } \\ \mathrm{N}_{2}, \mathrm{O}_{2} & & 0.0\end{array}$

Notes: "LANL" is Ref. 20; "Latimer" is Ref. 17; The derivation of the TBP value is discussed above.

From these values the energetics of the reactions can be derived as follows:

Reaction $\Delta \mathrm{H}, \mathrm{kcal} / \mathrm{mole}$

1.

2.

$-566.5$

$-374.7$

3.

$-421.4$

4.

$+30.5$

5.

$-522.0$

6.

$+89.1$

These equations were then fitted to the data of Nichols (ref. 6) assuming that (1) All nitric acid is consumed and appears as either nitrogen or $\mathrm{N}_{2} \mathrm{O}$. 
(2) $25 \%$ of the material reported as nitrogen was actually carbon monoxide.

(3) Some of the butanoic acid may have been lost before analysis.

The composite reaction was expressed as a linear combination of the above reactions, as follows:

$0.446(1)+0.112(2)+0.097(3)+0.05(4)+0.06(5)+0.318(6)$

From which a total reaction energy of $-337 \mathrm{kcal} / \mathrm{mole}$ was derived. This corresponds to the reaction of $1 \mathrm{~kg}$ of the TBP-nitric acid adduct, containing 3.44 moles of nitric acid.

These reactions correspond to the oxidation of a few per cent of the TBP present in this adduct. Only partial oxidation can occur, because of the limited amount of TBP present. This is the maximum amount extracted into the TBP phase under his conditions. The energetics are further reduced because the oxidation does not go to completion; intermediate products such as carbon monoxide, nitrous oxide, and butanoic acid remain. The reactions producing these products are less energetic.

The energy value resulting from these calculations ( $337 \mathrm{kcal} / \mathrm{kg}$ adduct) is used in this study for quantitative calculations because it is derived from measurements made at the relatively low temperatures encountered in canyon processes. Eisenhawer, in attempting to calculate the energetics in the Tomsk event, chose to use a bounding number about three times this value. 20 This could only be justified by assuming very concentrated (ca. $14 \mathrm{M}$ ) nitric acid in contact with the organic layer. Such acid concentrations are not encountered in the SRS canyons. The use of the energy for adduct decomposition, rather than the total energy for TBP oxidation, is justified by the need for intimate mixing to obtain efficient reactions. Note, however, that this value of $337 \mathrm{kcal} / \mathrm{kg}$ is approximately ten times higher than the values found by Barney and Cooper in well ventilated experimental apparatus. ${ }^{22}$ Their maximum value of $147 \mathrm{~J} / \mathrm{g}$ is about $35 \mathrm{kcal} / \mathrm{kg}$. This provides a measure of the heating potential that can be lost by the evaporation of reactants.

\section{Solubility}

TBP is soluble in water to about $0.4 \mathrm{~g} /$ liter, or about $0.04 \%$. While this dissolved material will hydrolyze and produce heat, its small amount and dispersion keep this portion of TBP from being a problem in most cases. However, when a saturated aqueous phase is concentrated the dissolved TBP will exceed the solubility limit and form a separate phase.

Water dissolves in TBP in appreciable amounts: up to $64.6 \mathrm{~g} /$ liter in pure TBP. Vaporization of this dissolved water could play a part in cooling the TBP in some scenarios. Its heat of vaporization is about $35 \mathrm{kcal} / \mathrm{liter}$ TBP $(146,000 \mathrm{~J} / \mathrm{liter})$. 


\section{Mechanisms for Heat Removal}

The concern in the TBP oxidation reactions is that the TBP phase will heat itself more rapidly than heat removal processes can remove the heat. These removal processes are therefore considered in turn.

a. For a thin layer in a large tank, heat removal through the tank wall in contact with the organic layer can be shown to be negligible. This is the case for the systems of interest at SRS.

b. Heat transfer by conduction or convection to the aqueous phase may be very important, as the organic layer contacts that phase. However, in the systems of most concern the aqueous phase is initially at the same temperature as the organic phase, and it can only take up heat after it has cooled or the organic phase has self-heated.

c. Evaporation of water may be a significant cooling method. If the aqueous phase is boiling, steam bubbles will bubble through the organic phase and carry away heat. Also, dissolved water in the organic phase can vaporize, as noted above. However, if the aqueous solution is quiescent, its evaporation will be hindered by the floating TBP layer, and the heat loss to evaporation will be restricted to that from the organic phase. This could be significant, especially for slow heating, as the evaporating water would be replaced by water diffusing in from below. However, the calculation would be complex, and has not been attempted here.

d. Convective cooling at the liquid surface may be the most important cooling method in many cases, and quantitative estimates of heat transfer by this process can be made. There are two cases to be considered. If the airflow is fast compared to the heating rate, then most of the heat will be carried away by the air circulating through the vessel. If the airflow is slow, the heating rate will be determined by the combination of convective heat transfer within the vessel, conduction through the vessel wall of the head space, and cooling of the wall by convective cooling at the exterior surface. The latter is a slower and less efficient process.

It is possible to show that for certain attainable conditions in the plant, using Nichols' heat values, the circulating air alone is sufficient to provide good cooling. The following sample calculations are all made for a large tank with a volume of 24.4 cubic meters and a surface area of 7.3 square meters. (This corresponds to a tank ten feet in diameter.) The airflow through the tank is assumed to be $50 \mathrm{cfm}$ ( $85 \mathrm{cubic}$ meters $/ \mathrm{hr}$ ) of air initially at a temperature of $30^{\circ} \mathrm{C}$.

Heat generation is calculated from the equation given by Nichols, over the range of frequency factors, which he measured. According to the Arrhenius equation, the half life of the reaction is calculated to be

$$
\mathrm{T}_{1 / 2}=\left(0.693 \mathrm{e}^{(26800 / \mathrm{RT})}\right) / \mathrm{F},
$$


with all units being cgs. Nichols measured $\mathrm{F}$ for three cases, according to whether the TBP had been contacted with (1) nitric acid, up to 10M; (2) $0.8 \mathrm{M}$ uranyl nitrate and $8.9 \mathrm{M}$ nitric acid; and (3) $1.5 \mathrm{M}$ uranyl nitrate and $3 \mathrm{M}$ nitric acid. The calculated rate constants as a function of temperature for these three cases are:

$\begin{array}{llll}\text { Temperature, }{ }^{\circ} \mathrm{C} & \mathrm{R}(1), \mathrm{hr}^{-1} & \mathrm{R}(2), \mathrm{hr}^{-1} & \mathrm{R}(3), \mathrm{hr}^{-1} \\ 80 & 0.0039 & 0.0022 & 0.00069 \\ 85 & 0.0066 & 0.0037 & 0.0012 \\ 90 & 0.011 & 0.0063 & 0.0020 \\ 100 & 0.030 & 0.017 & 0.0054 \\ 110 & 0.078 & 0.044 & 0.014 \\ 120 & 0.19 & 0.107 & 0.034\end{array}$

The cooling resulting from circulating air is calculated by a method suggested by J. E. Laurinat of the Savannah River Technology Center. In this method the heat transfer by turbulent natural circulation in a vertical cylinder is calculated according to the method recommended by Burmeister ${ }^{21}$, as follows:

Heat transferred from the vessel $=\mathrm{M} \mathrm{Cp}(\mathrm{To}-\mathrm{Ti})=\mathrm{h} \mathrm{A} \Delta \mathrm{T}_{\mathrm{lm}}$

Where the parameters are as follows:

$\mathrm{M}=$ mass of air entering the vessel per unit time

$\mathrm{Cp}=$ heat capacity of air at constant pressure

$\mathrm{Ti}=$ Temperature of air entering the vessel

To $=$ Temperature of air leaving the vessel

$\mathrm{h}=$ heat transfer coefficient, calculated below

$A=$ surface area of the vessel

$\Delta \mathrm{T}_{\mathrm{lm}}=\log$-mean temperature difference, calculated as follows:

$\Delta \mathrm{T}_{\mathrm{lm}}=(\mathrm{To}-\mathrm{Ti}) / \ln \left((\mathrm{Ts}-\mathrm{Ti}) /\left(\mathrm{Ts}-\mathrm{To}_{\mathrm{o}}\right)\right)$

where $\mathrm{Ts}$ is the temperature of the liquid surface.

$h$ is calculated from the properties of air and the dimensions of the vessel as follows:

$\mathrm{h}=0.12 \mathrm{k}(\mathrm{L} / \mathrm{D})\left(\mathrm{R}^{2} \mathrm{~g} \Delta \mathrm{T}_{\operatorname{lm}} \mathrm{Cp} / \mu \mathrm{k} \mathrm{Ti}\right)^{1 / 3}$

Where $\mathrm{k}=$ Thermal conductivity of air, $1004 \mathrm{~J} / \mathrm{kg} \mathrm{sec}$

$\mu=$ Viscosity of air, $0.0000185 \mathrm{~kg} / \mathrm{m} \mathrm{sec}$

$\mathrm{L}=$ Height of gas space above the surface

$\mathrm{D}=$ Diameter of the vessel

$\mathrm{R}=$ Density of air, $1.185 \mathrm{~kg} / \mathrm{m}^{3}\left(30^{\circ} \mathrm{C}\right)$

$\mathrm{g}=$ Gravitational constant, $9.8 \mathrm{~m} / \mathrm{sec}^{2}$ 
L/D was assumed to be 1.0 for these calculations. The numerical values above were obtained from Ref. 19. Variations with temperature were neglected.

As the equation for the heat is difficult to solve in closed form, the two expressions in equation (1) were calculated individually and To varied until the two agreed closely. A sample spreadsheet calculation is shown in Table A1. Data obtained over a range of temperatures were divided by the cross-sectional area of the vessel to give the heat loss per unit surface, as summarized here:

Temperature, ${ }^{\circ} \mathrm{C} \quad$ Heat out, $\mathrm{J} / \mathrm{sec}^{2}$

$80 \quad 159$

$85-177$

$90 \quad 193$

100225

110

$120 \quad 292$

Comparison of the heating and cooling data is shown in Figure 4. In this figure the depth of solution (and resulting mass) corresponding to the heat removed by convection is plotted for the three cases considered by Nichols: TBP contacted with nitric acid (Case 1, identified as "NA" in the Figure), TBP contacted with uranyl nitrate and strong nitric acid (Case 2, "UN/NA"), and TBP contacted with more concentrated uranyl nitrate and $3 \mathrm{M}$ nitric acid (Case 3, "UN").

As previously noted, this calculation does not consider the reduction in heating from the loss of volatile reactants, or other cooling effects. 
Table A1

\begin{tabular}{|c|c|c|c|c|}
\hline Parameters & Values & Units & Source & Name \\
\hline Cp (Air) & 1004 & $\mathrm{~J} / \mathrm{kg}{ }^{\circ} \mathrm{K}$ & Britt's Book & $\Phi$ \\
\hline$g$ & 9.80 & $\mathrm{~m} / \mathrm{sec} 2$ & $\mathrm{CAH}$ & $g$ \\
\hline$\mu$ (Air) & 0.0000185 & $\mathrm{~kg} / \mathrm{m} \mathrm{sec}$ & $\mathrm{CAH}$ & $\mathrm{Mu}$ \\
\hline$k$ (Air) & 0.038 & $\mathrm{~J} / \mathrm{m} \mathrm{sec}{ }^{\circ} \mathrm{K}$ & BSL & $k$ \\
\hline Air Density & 1.165 & $\mathrm{~kg} / \mathrm{m} 2$ & $\mathrm{CAH}$ & Rho \\
\hline $\mathrm{T}(\mathrm{TBP})$ & 353 & $K$ & Assumed & TTBP \\
\hline$T($ Air in) & 298 & \% & Assumed & TIn \\
\hline Area & 7.3 & $\mathrm{~m} 3$ & Assumed & $A$ \\
\hline$T$ (Air out) & 340.5 & K & Assumed & TOut \\
\hline Air Flow & 0.0235 & $\mathrm{~m} 3 / \mathrm{sec}$ & Assumed & Air \\
\hline$L / D$ & 1 & None & Assumed & LoverD \\
\hline$\Delta T I m$ & 28.6851173 & $K$ & Calculated & TIm \\
\hline Nu/L & 145.699963 & $1 / \mathrm{m}$ & Calculated & \\
\hline$h$ & 5.53659858 & $\mathrm{~J} / \mathrm{sec} \mathrm{m} 2{ }^{\circ} \mathrm{k}$ & Calculated & h \\
\hline Heat Out & 1168.19793 & $\mathrm{~J} / \mathrm{sec}$ & Calculated & $\mathrm{H}$ \\
\hline Heat Out Calc & 1159.37125 & J/sec & Calculated & HeatOut \\
\hline
\end{tabular}


Distribution List (U)

N. E. Barnett, 703-F

T. G. Campbell, 707-F

W. S. Cavin, 773-A

Michael Cowen, 992W-1

P. W. Dickson, 703-A

O. M. Ebra-Lima, 703-A

J. S. Evans, 703-F

Gregg Geiger, 992W-1

A. P. Gouge, 703-F

F. R. Graham, 773-A

J. H. Gray, 773-A

M. J. Hitchler, 992W-1

David Howard, 992W-1

D. R. Johnson, 707-H

J. Knight, 773-A

R. Maher, 703-A

John Marra, 703-H

J. G. McKibbin, 707-H

R. L. McQuinn, 703-F

A. P. Mock, 703-F

G. S. Nichols, 773-A

Kevin O'Kula, 992W-1

Don Paddleford, 992W-1

M. C. Thompson, 7730A 